\title{
MAKNA BERHIJAB BAGI MUSLIMAH: SEBUAH PERSEPSI MAHASISWI FISIP UNIVERSITAS MUHAMMADIYAH KENDARI
}

\author{
Oleh: Patta Hindi Asis \\ Dosen Jurusan Ilmu Sosiologi \\ Fakultas Ilmu Sosial dan Ilmu Politik \\ Universitas Muhammadiyah Kendari \\ E-mail: pattahindi@gmail.com
}

\begin{abstract}
Hijab is symbolyzed as marker modesty for moslem's women. Over time, it is not only seen as a loyalty, but as the existence of women in fashion in a community. In progress, Hijab follows liogic of market which eventually it makes for more fashionable just for business. This research explores of experience moslem's women using Hijab in a university in Kendari. Using a case study and experience of writer who interacts with student of moslem's women who wear the veil in a classroom are the method to collect the data. Critical Sociology is used as perspective of this study. This study found that some moslem's women wear hijab as religous view, and some stated only for lifestyle.
\end{abstract}

Keywords: Hijab, Hijab Commodification, Life Style.

\begin{abstract}
Abstrak
Jilbab adalah simbol agama islam sebagai penanda kesalehan perempuan. Seiring waktu jilbab tidak semata dimaknai sebagai bentuk kesalehan namun sebagai eksistensi sebagian perempuan dalam mode di tengah-tengah masyarakat. Dalam perkembangannya, jilbab mengikuti permintaan pasar, yang pada akhirnya jilbab dibuat lebih fashionable semata-mata agar laku dipasaran. Dengan menggunakan studi kasus dan pengalaman penulis berinteraksi dengan mahasiswi yang menggunakan jilbab di kelas adalah sebuah metode untuk mengumpulkan data. Sosiologi kritis digunakan untuk melihat fenomena dalam study ini. Penelitian ini menemukan bahwa sebagian muslim mempersepsikan dirinya bahwa jilbab adalah kepatuhan terhadap ajaran agama, sebagian menyebutkan bahwa memilih ber-jilbab karena tuntutan gaya hidup.
\end{abstract}

Kata kunci: Jilbab, Komodifikasi Jilbab, Gaya Hidup.

\section{Pendahuluan}

"Hai Nabi! Katakanlah kepada istri-istrimu, anak-anak perempuanmu dan istri-istri orang mu'min: "Hendaklah mereka mengulurkan jilbabnya ke seluruh tubuh mereka. Yang demikian itu supaya mereka lebih mudah untuk dikenal, karena itu mereka tidak diganggu."

(Q.S. Al-Ahzab: 59)

'hendaklah mereka menutupkan kain kerudung ke dada...'(Annur: 31). 
Untuk beberapa orang, jilbab adalah kesederhanaan, kedekatan dengan pencipta dan pelindung diri sebagai perempuan Muslim. Bagi sebagian yang lain, hijab adalah gaya hidup, modernitas, mobilitas, dan identitas diri dalam pergaulan di tengah-tengah masyarakat.

Dua kutub ini selalu berkelindan dalam kehidupan perempuan Muslim di Indonesia. Dua pandangan ini memiliki rasionalisasi sendiri atas pemaknaan menggunakan pelindung diri yang disebut sebagai istilah Jilbab, Hijab, dan Kerudung ${ }^{\mathrm{i}}$ di masyarakat Indnonesia. Penggunaan jilbab bagi perempuan muslim tidak lepas dari ruang dimana mereka hidup. Jilbab selalu berkaitan baik secara langsung maupun tidak berkait erat sesuai latar belakang pendidikan, budaya, dan pandangan hidup seseorang. Setidak yang terjadi di dua negara hasil penelitian Kenneth Jackson \& Elizabeth Turneri ${ }^{\mathrm{ii}}$. Mereka melihat perbedaan pakaian muslimah di kedua negara tersebut. Di Cairo, para perempuan memakai hijab, sedangkan di Sana'a mayoritas perempuannya menggunakan niqab. Menurutnya nikab adalah bagian yang menutupi wajah. Seluruh setelah pakaian menutupi wajah. Jackson dan Turner menyebutkan bahwa berbeda dengan nikab hijab tidak semudah yang dibayangkan (hanya menutup kepala dan rambut):

Its also to keep in mind that concept of hijab involves more than covering just the head and hair. Some of the women of this study that the hijab means more than simply the attire worn; it is act of meodesty in terms of behavior that goes along with wearing the hijab. Some also consider the hijab to represent all form of dress.

Di Indonesia, perempuan muslimah lebih sering menggunakan hijab dalam segala aktifitas di kantor, di kampus maupun saat bersantai. Hijab menjadi pakaian formal bagi perempuan muslim. Di atara perempuan memilih hijab berdasarkan atas persepsi ketaaan pada syariah, sedang yang lain menganggap sebagai pragmatis saja: fashionable.

Di kalangan mahasiswa sendiri, penggunaan jilbab sudah mulai berkembang di tahun 90-an. Mahasiswa di universitas-universitas muslim seperti UIN, STAIN, dan UNISMUH diwajibkan mahasiswa memakai jilbab. Tidak hanya di kampus-kampus muslim, kampus umum telah banyak mahasiswa yang beralih menggunakan jilbab sebagai pakaian dan gaya hidup. Persentase mahasiswa di kampus umum yang menggunakan jilbab diperkirakan sudah mencapai di atas 60 persen $^{\text {iii }}$.

Di kalangan mahasiswa UNISMUH Kendari dan kampus yang dimiliki oleh persyarikatan Muhammadiyah, seluruh mahasiswi menggunakan jilbab (mahasiswi selain Islam, biasanya menyesuaikan). Menjadi tantangan adalah sebagian mahasiswa menggunakan jilbab dianggap 
sesuai syariah dan sebagian lagi menggunakan jilbab sesuai dengan mode masa kini yang lazim disebut hijabers ${ }^{\mathrm{iv}}$.

Dua kutup ini berkelindan dalam kehidupan perempuan muslim terutama di kalangan mahasiswi Universitas Muhammadiyah Kendari. Penggunanan jilbab bagi mereka tidak semata-mata taat pada ajaran agama namun semata-mata memakai dengan alasan praktis agar mereka terlihat tidak 'mati gaya'.

Dari latar belakang diatas, menarik untuk ditemukenali lebih jauh pemaknaan menggunakan jilbab di kalangan mahasiswa fisip Universitas Muhammadiyah Kendari yang memiliki ragam dalam menggunakan jilbab. Tulisan ini menyoal pada komodifikasi jilbab yang kini marak digunakan oleh mahasiswi di kampus muslim swasta tersebut dengan pendekatan sosiologi kritis.

\section{Perkembangan Jilbab di Indonesia}

Secara istilah jilbab, hijab, dan kerudung adalah menutup bagian tubuh seperti kepala. Bagi masyarakat di Indonesia terminologi tersebut sering saling menggantikan. Kadang disebut jilbab, lain waktu disebut kerudung. Sampai sekarang penamaan ini masih menjadi silang pendapat di masyarakat.

Jika lebih ditelusuri perkembangannya, masyarakat umumnya di Indonesia menyebut seseorang yang menutup aurat (terutama kepala) disebut 'berkerudung' dan marak terjadi di tahun 1970-an. Setelah beberapa dekade, di awal tahun 1980-an. Muncul istilah yang lebih popular: jilbab ${ }^{\mathrm{v}}$

Konsep jilbab mengandung arti sebagai ketataan terhadap perintah agama dalam menutup aurat. Aurat perempuan menurut Islam adalah seluruh tubuh kecuali muka dan telapak tangan. Aurat tidak diperlihatkan ke orang lain kecuali terhadap suami atau mahramnya (saudara atau kerabat dengan kriteria tertentu).

Secara aplikatif, dalam pakaian dijumpai dengan perempuan yang menutup aurat dengan jilbab atau hijab. Faktanya, banyak perempuan memaknai jilbab tidak hanya sekedar menggugurkan kewajiban agama, namun mengikuti trend fashion/mode. Tidak heran sebagian perempuan memakai jilbab dengan model dan ragam tertentu dengan paduan jeans atau celana ketat. 
Umumnya para ahli fiqh sepakat menyimpulkan bahwa aurat perempuan meliputi seluruh tubuh kecuali muka dan telapak tangan. Namun sebagian ada yang mengatakan bahwa telapak kaki termasuk yang dikecualikan. Tujuan menutup aurat adalah larangan mempertontonkan keindahan tubuh. Konteks sekarang bagi sebagian yang menganggap jilbab adalah gaya hidup memaknai pemakaian jilbab cenderung memiliki sifat "kompromistis" antara budaya yang islami dan budaya modern (jilbab-jeans).

Jilbab atau hijab menjadi industry yang menguntungkan. Dengan jumlah populasi muslim terbesar di dunia, Indonesia menjadi pasar besar dalam industry pakaian muslim (muslim fashion). Termasuk jilbab, beraga merek dan ragam model dan warna, vendor secara massif menawarkan jilbab untuk mempengaruhi cara berpakaian perempuan muslim di Indonesia.

Komodifikasi di abad ini sudah menggejala di masyarakat modern, fenomena ini terjadi diberbagai sendi kehidupan, berlanjut dalam aras sosial dan budaya hingga aras kehidupan agama khususnya pemakaian simbol-simbol agama. Penggunaan simbol agama seperti halnya jilbab menjadi arena pasar untuk mendapatkan keuntungan ekonomi.

Sejak kemunculannya di negeri arab, jilbab terus mengalami transformasi baik dari segi pemaknaan maupun segi gaya dan model. Jilbab dulu hanya memakai satu warna saja (dominan hitam atau putih), namun dewasa ini jilbab kini didominasi dengan warna-warni, beragam motif, dan asesoris tambahan lainnya. Di Indonesia sebagai kasus, sejak kemunculannya di era 70-80 dikenal dengan jilbab "Ida Royani" yang di perkenalkan oleh bintang era 70an Ida Royani. Setelah itu, tahun 90-an muncul Neno Warisman dengan model jilbabnya "Rabbani", tahun 2000an muncul model jilbab bergaya "Inneke Koesherawati" hingga model "Manohara" dan "Faira". Sekarang ini sudah sulit dihitung dengan jari model jilbab yang berkembang di tanah air yang dijual secara online atau offline.

Semangat zaman ini dimodifikasi ke dalam simbol-simbol agama dari logika produksi ke logika konsumsi. Penggunaan jilbab pada akhirnya bergerak dalam logika komodifikasi yang perlahan menggerus makna sesungguhnya dari ber-jilbab syar'i.

Dalam pandanan syariat, dapat dikatakan jilbab atau hijab merupakan busana untuk muslimah yang tidak ketat atau longgar dengan ukuran besar yang menutup seluruh tubuh perempuan kecuali muka dan telapak tangan. Pengertian ini sedikit berbeda dengan arti jilbab yang selama ini dipahami di Indonesia yang identik dengan penutup kepala atau kerudung saja. 
Jilbab pun diproduksi berdasarkan gaya hidup masyarakat Indonesia yang sebagian besar terpengaruh cara berpakaian ala barat.

Gejala komodifikasi atas jilbab ini membuat perempuan yang mengenakan jilbab tidak selalu berhasil membangun klaim heroik bahwa jilbab yang dikenakannya adalah bentuk ikhtiar sadar diri untuk melawan pesona ke-molek-an, ke-trendi-an, dan seperti yang jamak dijual oleh kalangan industri mode/fashion sekarang ini. Hal ini menandakan bahwa jilbab sekarang tidak hanya di dominasi atas kesalehan pada keyakinan, namun juga pada ketundukan pada logika mode/fashion.

\section{Trend Hijab Sebagai Industri}

Jilbab menjadi industry yang tumbuh pesat sekarang ini. Faktanya produk dari merek dagang terkenal menyesuaikan tuntutan perempuan muslim untuk mobile sekaligus fashionable dalam memakai jilbab. Maka diproduksilah jilbab bergaya sport. Faegheh Shirazi, Professor Di Department Studi Timur Tengah Universitas Texas Amerika mengungkapkan hasil penelitiannya di sebuah artikel (http://theconversation.com) $)^{\mathrm{vi}}$ mengungkapkan bahwa industry hijab adalah industry yang berkembang pesat terutama di Eropa. Di Indonesia, industry hijab juga tumbuh pesat dengan beragam merek dagang dan model.

Sejarah perkembangan mode muslim jika merujuk pada penelitian Shirazi terutama di Eropa Barat terjadi pada tahun 1980-an ${ }^{\text {vi }}$ ketika negara-negara Eropa dan Amerika mengimpor pakean muslim bagi penduduk muslim di negara tersebut. Dan dampknya sangat besar, dan menjadi bisnis sukses. Dan berkembang hingga kini.

Di Indonesia bisnis mode pakean muslim mulai berkembang di era tahun 2000-an. Pakean muslim menjadi sukses setelah beberapa artis terkenal Indonesia seperti Inneke Kushewati, dan desainer Dian Pelangi memperkenalkan hijab yang lebih nuansa modern di pasaran. Sejak saat itu banyak bermunculan merek-merek dagang yang memproduksi jilbab secara massal beberapa diataranya Rabbani, dan Zoya.

Revolusi fashion telah mempengaruhi gaya dan model jilbab. Model-model jilbab sekarang didominasi oleh produk modern yang lebih trendy, gaul dan fasionable. Tiap tahun merek dagang menawarkan model dan warna baru, jilbab menjadi komoditas. Produk-produk pun dibuat secara standar dengan mengikuti model modern tanpa memperhatikan lagi aspek "fiqh" jilbab. 
Realitas mahasiswi FISIP Unismuh Kendari, sebagian orang mengenakan secara ala kadarnya dan bahkan cenderung 'jilbab lepas’ (baca: jilbab gaul). Sebagian lagi mengenakannya secara 'moderat', tidak ketinggalan mode tapi juga tidak mengabaikan kaidah syar'i. Sementara sebagian kecil yang lain cenderung terlalu bersemangat dengan pilihan hijab seperti di negeri arab bahkan kadang kala ditambah dengan burka.

Melihat beragamnya model dan gaya orang berjilbab maka mengaitkan jilbab dengan Islamisasi menjadi kesimpulan yang tergesa-gesa atau sebagai kesimpulan yang terlalu melompat (baca: jumping). Penggunaan jilbab di kampus tersebut tidak lepas dari latar belakang social budaya mahasiswi.

Munculnya industri jilbab dengan beragam bentuk, model, harga dan iklan dan citra-citra modenya menandakan sebuah komodifikasi jilbab. Jilbab menjadi industri yang menguntungkan dalam pasar di Indonesia. Jilbab "manohara" dan "rabbani” sampai "jilbab paris" telah menjadi model tersendiri dalam kehidupan industri jilbab tanah air. Jilbab juga telah menjadi arena pertarungan para industri global, misalnya saja produk-produk jilbab banyak produksi China yang membanjiri pasar di Indonesia, hijab sport keluaran Nike dan beragam produksi lainnya dari merek dagang global.

Apa yang terjadi di sebagian Mahasiswi Fisip Universitas Muhammadiyah Kendari dengan penggunaan jilbab tidak sekedar tahu syariah namun juga mode terkini. Akhirnya, penggunaan jilbab tidak hanya sebatas kebutuhan ruhani, namun pemuasan citra diri. Bagi sebagian mahasiswi, jilbab yang agak longgar, memakai rok menandakan indentitas pada ideologi tertentu yang cenderung moderat, ada juga yang jilbab dengan paduan jeans yang "melek" modernisasi, memadukan jilbab dengan celana jeans yang cenderung terlihat trendi sebagai indentitas modern. Untuk lebih memberi gambaran jelas tentang jilbab yang menurut Suciwaty - dianjurkan oleh fiqh islam dan jilbab modern. Ilustrasi dibawah ini menegaskan, transformasi jilbab tidak sekedar hanya pemenuhan nilai-nilai religius, namun fashion menjadi tanda penting dalam menafsirkan jilbab modern (baca : jilbab gaul).

\section{Metode Penelitian}

Penelitian ini sifat studi literature namun penulis menggunakan pendekatan studi kasus dengan metode pengumpulan data melalui wawancara tidak terstruktur dan angket dengan maksud memberikan gambaran utuh suatu fenomena. Wawancara dilakukan bersifat terbuka dengan memberikan kesempatan luas kepada mahasiswi yang mempersepsikan diri 
menggunakan jilbab. Angket kemudian disebarkan di kelas kepada mahasiswi. Jumlah mahasiswi FISIP yang aktif saat ini mencapai kurang lebih 500 orang seluruh angkatan. Mengingat jumlah mahasiswa sebagai sumber informasi sangat banyak maka penelitian ini hanya membatasi mahasiswa baru angkatan baru 2017 yang berjumlah 50 orang. Kemudian dipilih secara purposive dengan jumlah $10^{\text {viii }}$ orang karena mahasiswa dianggap homogen (semua menggunakan jilbab). Setelah itu, peneliti mengelompokkan mahasiswi berdasarkan klasifikasi tertentu seperti model jilbab dan latar belakang social budaya mahasiswi.

Analisis data menggunakan metode kualitatif yang menekankan pada kedalaman dan pemaknaan masalah yang diteliti. Data yang dikumpulkan, ditranskrip, di analisis kemudian dielaborasi guna menjawab permasalahan. Adapun data-data yang bersifat statistik digunakan sebagai pendukung analisis.

\section{Kesan Ber-Jilbab di Kalangan Mahasiswa Baru}

Hasil angket yang dibagi pada mahasiswa baru angkatan 2016/2017, dari 30 kuesioner sesuai dengan jumlah mahasiswa perempuan dalam satu angkatan tersebut hanya 17 yang mengisi dan mengembalikan angket.

Setelah data dikumpulkan, penulis kemudian mengolah angket tersebut kedalam aplikasi pengolah data statistik sederhana yaitu Microsoft Excel. Tentu dengan jumlah responden yang sedikit agaknya sulit untuk mengukur secara utuh persepsi mahasiswi tentang makna berjilbab. Dan penulisan artikel ini tidak berpretensi penelitian kuantitatif, namun untuk mengukur trend persepsi diri mahasiswa di FISIP Universitas Muhammadiyah Kendari mengenai hijab yang bisa menjadi informasi menarik dengan beberapa 'temuan' kecil ini. Hal ini termasuk wawancara lepas penulis kepada mahasiswi yang mengenakan jilbab yang menyebut diri mereka jilbab syar'i.

Secara umum, temuan-temuan itu dapat dirangkum sebagai berikut:

- Mahasiswi baru pada umumnya berasal dari luar kota Kendari namun masih dalam satu wilayah provinsi Sulawesi Tenggara. Mereka datang dengan latar belakang orang tua yang pada umumnya bekerja sebagai petani. 
- Mereka telah mengenal dan mengenakan hijab sejak masuk SMP dan SMA. Mahasiswi baru mengenakan hijab jauh sebelum masuk di bangku kuliah

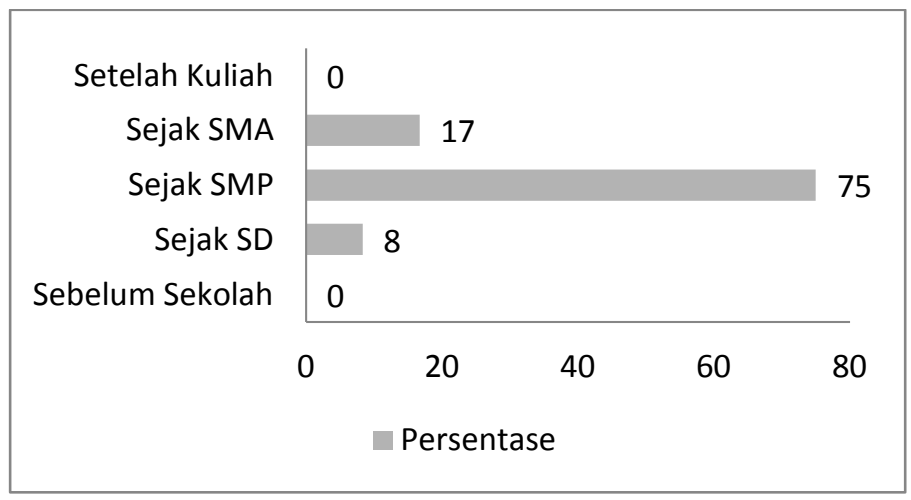

- Mereka mengetahui bahwa mengenakan jilbab adalah kewajiban seorang muslimah yang sudah diatur dalam alquran. Juga mengetahui bahwa jilbab musti menutup aurat

- Namun mereka persepsikan bahwa hijab musti menyesuaikan tren, mode dan gaya terkini agar dapat menyesuaikan penampilan mereka.

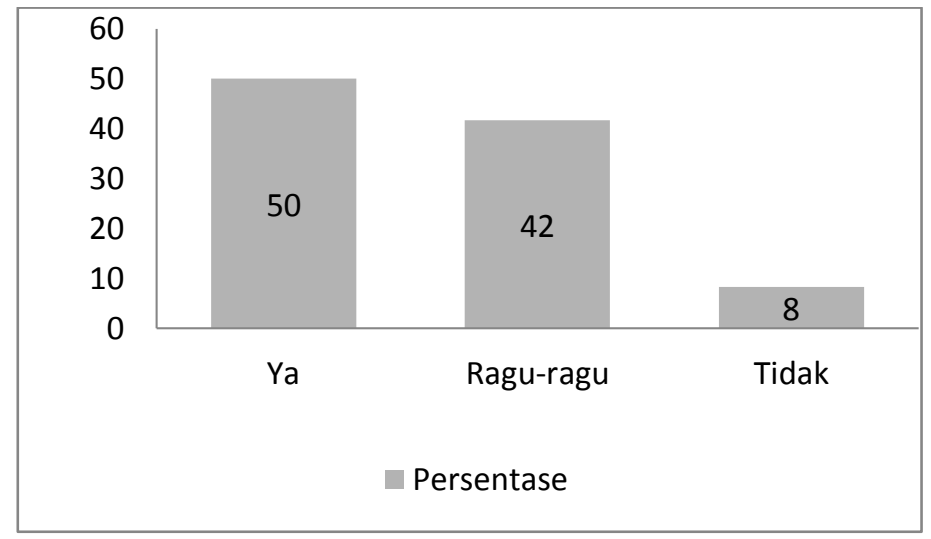

- Mereka sangat percaya diri mengenakan jilbab sebagai identitas mereka dalam aktifitas sehari-hari.

- Pada umumnya, mahasiswi baru tersebut selalu melepas jilbabnya ketika pulang atau di luar kampus.

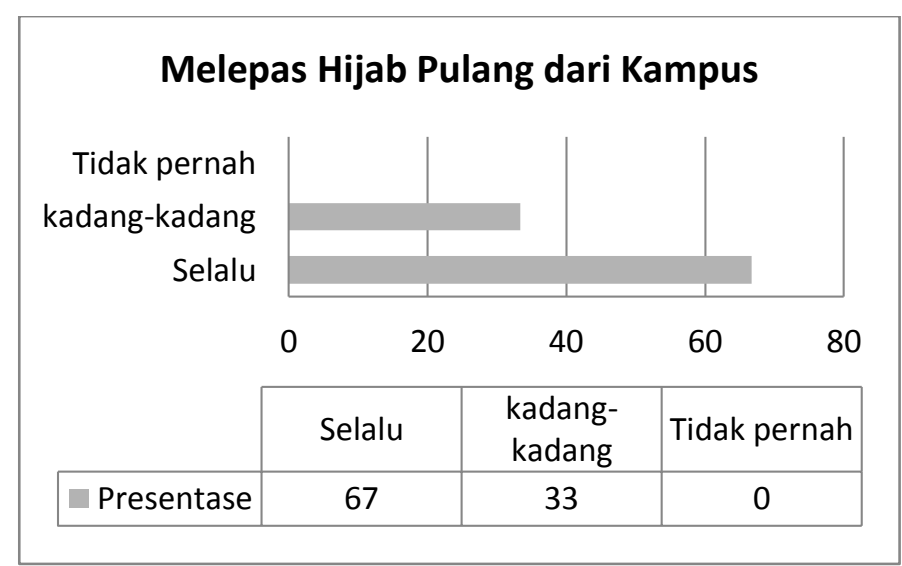

- Mereka mempersepsikan diri sebagai kelompok hijabers. 
- Bagi kelompok jilbab syar'i, jilbab atau hijab ada kewajiban sebagai perempuan muslim. Menurut mereka seorang perempuan terlihat elegan dan jauh dari fitnah ketika mengenakan jilbab yang sesuai dengan tuntunan syariah.

Hal tersebut mengilustrasikan bahwa kesan mereka berhijab atau berjilbab di satu sisi ada ketaatan dalam perintah agama yang setiap perempuan muslim wajib menutup aurat namun disisi lain mereka mengenakan jilbab namun mengikuti trend hijab kekinian yang penuh dengan aksesoris.

Persepsi dalam penggunaan jilbab di kalangan mahasiswi cenderung terbagi dalam kelompok-kelompok. Namun yang lebih jelas adalah kelompok yang menganggap jilbab adalah keharusan dan ketaatan dalam perintah agama (jilbab syari’i) sedangkan kelompok lainnya menganggap jilbab berkaitan mode dan gaya hidup (hijabers).

Singkatnya, persepsi tentang jilbab tidak berada dalam ruang hampa. Ia berasal dari pemaknaan individu atau penghayatan terhadap norma dan nilai-nilai dasar yang berlaku dalam masyarakat. Proses ini disebut Peter L. Berger sebagai tafsir atas realitas social. Berger melihat Individu sebagai bagian dari masyarakat yang terus mengalami dinamika dan bersifat dialektis. Dalam moment tersebut setidaknya terjadi momentum yang disebutnya dalam tiga istilah: eksternalisasi, obyektifikasi dan internalisasi. ${ }^{\text {ix }}$

Penghayatan terhadap berjilbab adalah proses dialektis terhadap diri seseorang, fenomena terbaru artis Rina Nose ${ }^{\mathrm{x}}$ yang menanggalkan jilbabnya adalah salah satu contoh suasana batin seseorang dalam berjilbab. Awalnya sang artis tidak menggunakan jilbab-berjilbab-melepas jilbab contoh proses dialektis individu dalam memaknai realitas.

Proses ini disebut Berger sebagai proses dialektis indvidu dalam keberadaanya di masyarakat. Seseorang berjilbab awalnya dimulai dari mengenal, penyesuaian dan akhirnya menggunakan jilbab. Pemakaian jilbab dekat dengan keterpanggilan. Max Weber menyebut ini sebagai Beruf (calling), yang terpanggil. Seseorang mengenakan jilbab karena merasa terpanggil oleh Sang Ilahi (ilahiyah).

Terkait dengan kehidupan penggunaan hijab di kalangan mahasiswa, kehidupan mereka mencoba untuk menemukenali kelompok-kelompok yang sesuai dengan gaya jilbab mereka. Walaupun mereka tidak membeda-bedakan diri dalam pergaulan di kelas (inklusif) namun dalam kesempatan lainnya di luar kampus mereka membentuk atau bergabung dalam komunitas-komunitas jilbab. Dan yang paling nampak adalah kelompok jilbab hijabers. Hal 
yang menarik adalah mereka menganggap jilbab mereka telah sesuai dengan syariah dengan menutup aurat. Yang membedakan, mereka mempersepsikan diri telah menyesuaikan dengan gaya terkini agar lebih terlihat fashionable.

\section{Komodifikasi Jilbab}

Hasil amatan tersebut memperlihatkan bahwa jilbab telah mengalami transformasi komoditas yang tidak hanya didasarkan lagi pada nilai-nilai luhur agama, namun tunduk pada produksi tanda yang terkesan 'gaul'.

Globalisasi telah menciptakan gelombang masyarakat yang dalam istilah Ulrich Bech adalah Masyarakat Beresiko. Menurut Beck (Ritzer \& Goodman, 2008) bahwa kita masih hidup dalam kehidupan modern yang kemunculannya berkaitan dengan masyarakat beresiko ${ }^{\mathrm{xi}}$.

Menurut Ritzer \& Goodman, masyarakat beresiko dapat dilihat sebagai sejenis masyarakat industri karena kebanyakan risikonya berasa dari industry. Walaupun industry hijab belum menciptakan masyarakat beresiko namun perlahan dalam industry hijab secara global telah menciptakan masyarakat konsumtif yang membawa risiko yaitu masyarakat konsumtif. Seseorang meggunakan lagi semata-mata karena panggilan ilahiah namun karena ingin memuaskan hasrat belanja jilbab yang kekinian.

Terkait dengan yang terjadi di kalangan mahasiswa, persepsi diri mereka terhadap gaya berjilbab adalah masuk dalam kategori hijabers (lihat tabel). Persentase cukup besar dari keseluruhan responden yang mengidetifikasi dalam kelompok hijabers. Menjadi rahasia umum bahwa kelompok hijabers adalah kelompok atau komunitas yang menggunakan hijab yang mengikuti trend dengan bermacam motif dan asesorisnya.

Fenomena ini menjadi pintu masuk bagi produk jilbab secara global. Globalisasi telah memberi angin segar bagi komodofikasi barang yang setiap waktu menerabas ke dalam sendi-sendi kehidupan agama. Globalisasi tidak hanya menyentuh dalam ekonomi namun sudah merasuk dalam sendi-sendi sosial budaya budaya masyarakat, termasuk juga industri Jilbab. Jilbab sebagai komoditas bagi masyarakat Indonesia menjadi barang yang laku dipasaran dengan model yang beragam. Masyarakat sebagai obyek dalam industry ini menjadi arena kontestasi dalam mengeruk keuntungan yang akhirnya bermuara pada konsumsi secara massa. 
Paul Willis (1990) yang dikutip Cris Barker (2009) ${ }^{x i i}$ menyatakan proses komodifikasi menegaskan adanya 'budaya bersama' (common culture) dalam mengonsumsi praktik yang dilakukan anak muda alih-alih makna dan nilai dalam pemakaian aktual. Ini yang disebut estetika yang membumi. Willis menambahkan penonton merupakan pembaca citra yang mahir.

Dengan industri komodifikasi, simbol agama (baca jilbab) menjadi arena dalam memproduksi secara massal dengan tujuan komoditas barang dagangan. Simbol agama sebagai dagangan yang dipajang di mal-mal, butik dan pasar dibantu dengan iklan artis dan televisi. Dengan komodifikasi seperti itu, manusia dijadikan layaknya subjek yang pasif, hanya melihat citra dari televisi maupun artis yang memasarkan simbol tersebut. Dan semakin laris di pasar.

Baudrillard (2009) ${ }^{\mathrm{xiii}}$ menjelaskan pengetahuan dasar tentang kebutuhan berhubungan erat dengan pengetahuan dasar tentang kemapanan dalam mistik persamaan. Tesisnya menandakan semua sama dalam nilai tanda. Tidak yang miskin maupun orang kaya.

Ritzer dalam pengantarnya di buku Masyarakat Konsumsi, mengeintrodusir pemikiran Baudrillard, konsumsi bukan sekedar nafsu untuk membeli bagitu banyak komoditas, satu fungsi kenikmatan, satu fungsi individual, pembebasan kebutuhan, pemuasan diri, kekayaan, atau konsumsi objek. Konsumsi berada dalam satu tatanan pemaknaan pada satu "panoply" objek; satu sistem, atau kode, tanda; satu tatanan manipulasi tanda.

Pergulatan konsumsi jilbab memang tidak memiliki partisi jelas lagi, semua tertuju pada konsumsi tanda, sebagai contoh jilbab yang memiliki merek tertentu. Si-Pemakai tidak semata-mata membeli karena harga dan kualitas tetapi membeli berdasarkan merek barang, model dan aseoris lainnya. Ilustrasi ini tepat yang dikatakan Baudrillard, mengkonsumsi tanda.

Dalam industri jilbab terjadi relasi kuasa antara pemilik industri jilbab dan si-pengguna jilbab. Jilbab menjadi dagangan yang menguntungkan. Pemilik modal mencari celah bahwa dengan kewajiban umat muslim untuk mengenakan jilbab maka untuk mengeruk keuntungan dicipatakan jilbab yang lebih fashionable dan sesuai tuntutan zaman. Setiap tahun jilbab berubah bentuk, model dan warna yang mengakibatkan komodifikasi terus menerus untuk mendapatkan keuntungan sebanyak-banyaknya. 
Ajaibnya karena masyarakat yang memakai jilbab cenderung lebih memilih motif modern dan warna-warni. Celah itulah yang digunakan merek dagang untuk memproduksi jilbab. Disinilah titik semu antara ketundukan akan penghayatan agama dengan ketundukan dalam mengkosumsi citra budaya konsumtif dipertemukan. Bagi umat muslim, memakai jilbab adalah kewajiban agama disatu sisi. Namun di sisi lainnya, tuntutan akan mode dan trend 'memaksa' seseorang untuk menyesuaikan diri. Ada yang bertahan dengan jilbab yang dimaksud oleh tuntunan syar'i tapi tidak sedikit sekedar memakai jilbab karena ingin terlihat fashionable.

Untuk membendung infiltrasi ideology jilbab kekinian, beragam ide kritis muncul sebagai sarana kontrol dalam melihat fenomena konsumsi jilbab di masyarakat sebagai alternatif dalam membendung konsumsi massa terhadap jilbab yang tidak sesuai dengan syariah diantaranya apa yang dikemukakan Elis Zuliati Anis dalam artikelnya mengenai Islam ala Iklan $^{\text {xiv }}$ menyimpulkan sebaiknya masyarakat tidak terlena dan asal percaya pada symbolsimbol agama ala media. Pentingnya pendekatan kritis melihat fenomena komodifikasi symbol agama di media dan endorser iklan agar terjadi kesadaran kritis terhadap globalisasi jilbab yang telah bermuara pada komodifikasi yang menihilkan esensi berjilbab itu sendiri.

Produk-produk jilbab yang terus di komodifikasi dengan label "islam" terpampang di malmal, butik, distro hingga pasar tradisional. Berlindung dengan semangat syariah, jilbab menjadi barang laku di pasaran. Baudrillard mengatakan :

...perkara konsumsi yang menyeluruh, tidak ada lagi ruh, bayangan, salinan, gambar dalam arti spektakuler. Tidak lagi ada lagi kontradiksi dengan manusia individu yang terhapus dalam kombinasi ini dan perhitungan tanda-tanda... ${ }^{\mathrm{x}}$

Masyarakat konsumsi telah melebur menjadi citra tanda, kondisi ini lahir di masyarakat yang mengkonsumsi jilbab, citra tanda menjadi penting dari sekedar seruan agama untuk menutup aurat (pada intinya jilbab adala hijab untuk menutup aurat). Dilema ini menurut Baudrillard akan menuju pada proses alienasi masyarakat konsumsi. Sedangkan Cris Barker menyebutnya fenomena ini dengan kebudayaan tanpa kedalaman. Barker yang mengutip Jameson $(1984)^{\mathrm{xvi}}$ pascamodernisme terlibat dalam kesadaran yang dangkal tentang masa kini dan kehilangan pemahaman historis. Menurutnya manifestasi spesifik itu terdiri dari (a) Kanibalisasi gaya dari masa lalu dan masa kini, (b) Hilangnya gaya artistik autentik karena digantikan oleh (pastiche), (c) Transformasi representasi dunia menjadi citra dan tontonan, (d) Runtuhnya perbedaan yang tegas antara budaya rendah dengan budaya tinggi (e) Kebudayaan simulacrum atau tiruan (dimana tidak ada lagi yang asli) (f) Fashion untuk 
nostalgia sehingga sejarah bukan lagi objek representasi melainkan objek konotasi stilistik. Barker menambahkan bahwa dunia pascamodern sebagai suatu yang ditandai dengan fragmentasi, instailitas dan disorientasi banyak memiliki kesamaan dengan Baudrillard.

\section{Simpulan dan Diskusi}

Jilbab telah menjadi gaya hidup bagi mahasiswi FISIP dalam kegiatan akademik. Fenomena ini melengkapi ikon sebagai kampus yang berahlaqul karimah. Namun pengguna jilbab tidak sepenuhnya paham tentang arti pentingnya berjilbab sebagai seorang muslimah. Bagi sebagian mahasiswi, jilbab adalah ketaatan terhadap perintah agama sedang sebagian lainnya menganggap jilbab adalah identitas diri dan gaya hidup. Sehingga mahasiswa FISIP Unismuh Kendari dapat mudah diidentifikasi menjadi beberapa kelompok. Pertama, jilbab syari’i yaitu kelompok yang menyebut dirinya sadar akan pentingnya berjilbab sesuai tuntunan syariah. Kelompok kedua adalah jilbab modern, yang menyebut diri hijabers. Kelompok yang menyesuaikan dengan gaya hidup dan mode pakaian muslim terkini dan cenderung memilih jilbab berdasarkan model, warna dan asesoris tertentu.

Masifnya industry mode muslim dewasa ini musti disikapi secara bijak bahwa setiap komodifikasi produk industry tidak lepas dari motif ekonomi. Komodifikasi symbol-simbol agama disalurkan melalui media dan pendukung iklan melalui artis dan orang-orang terkenal. Komodifikasi ini sebagai upaya mempengaruhi masyarakat melalui kesan dan citra yang islami sekaligus modern yang bisa mempengaruhi masyarakat larut dalam budaya konsumtif. Oleh karena itu perlu upaya-upaya diantaranya, Pertama, perlunya kesadaran kritis dan kesadaran religius masyarakat dalam melihat fenomena jilbab, tidak hanya sekedar mengkonsumsi tanda dalam arena sosial. Dibalik semua itu ada relasi kuasa pemilik modal untuk mendapatkan keuntungan besar dengan berlindung di balik simbol-simbol agama. Seseorang yang sudah terjebak di dalamnya berarti telah jatuh pada konsumerisme.

Kedua, perlu memposisikan diri yang tepat terhadap ajaran agama dan yang melekat padanya. Menghindari keterjebakan dalam simbol, mendalami esensi ajaran, dan berupaya melaksanakan dalam kehidupan, tidak saja dalam lingkungan keluarga namun juga di kampus.

Ketiga perlu pemahaman yang lebih komprehensif mengingat jilbab tidak menjadi tolok ukur atau standar religiusitas seseorang. Jilbab adalah cara berpakaian yang sangat terhormat bagi perempuan muslim walau batasan tentang jilbab di masih terjadi silang pendapat diantara 
alim ulama juga di masyarakat. Namun yang penting adalah bagaimana pengguna jilbab menggunakan jilbab yang sepantasnya dan tidak larut dalam konsumerisme.

\section{Referensi}

Aniz Z. Elis. 2013. Islam Ala Iklan: Komodifikasi Indentitas Keislaman Dalam Iklan di

Televisi Indonesia (Makalah diterbitkan). Jurnal dapat di unduh di: http://download.portalgaruda.org/article.php?article=360819\&val=7520\&title=Islam\%20Ala \%20Iklan\%20\%20Komodifikasi\%20Identitas\%20Keislaman\%20dalam\%20Iklan\%20Di\%20 Televisi\%20Indonesia

Barker, Cris, 2009. Cultural Studies : Teori dan Praktik, Kreasi Wacana, Yogyakarta.

Berger L. Peter \& Luckman, Thomas. 1990. Tafsir Sosial Atas Kenyataan. LP3ES. Jakarta (terjemahan dari The Social Contruction of Reality: A Treatise in In the Sociology of Knowledge.

Baudrillard, P. Jean, 2009. Masyarakat Konsumsi, Kreasi Wacana, Yogyakarta.

Budiastuti. 2012. Jilbab Dalam Perspektif Sosiologi, FISIP UI. Tesis (tidak dipublikasikan)

Nugroho, Heru, 2003 (edisi revisi). Menumbuhkan Ide-ide Kritis, Pustaka Pelajar, Yogyakarta.

Jackson E. Kenneth, Monk-Turner, Elizabeth. 2015. The Meaning of Hijab: Voices of Muslim Women in Egypt and Yemen. Journal of International Womens Studies volume 16. Bridgewater State University. Tersedia di http//vc.bridgew.edu/jiws/vol16/iss2/3

Ritzer, George \& Goodman J. Douglas. 2008. Teori Sosiologi Modern. Kencana. Jakarta. (terjemahan dari Modern Sociological Theory, $6^{\text {th }}$ Edition).

\section{Internet}

http://theconversation.com/how-the-hijab-has-grown-into-a-fashion-industry-74740 (diakses Selasa 30 Oktober 2017) 


\footnotetext{
' Penggunaan istilah tersebut dimaknai berbeda di masyarakat Indonesia. Bagi sebagian orang, Hijab untuk mereka yang menggunakannya secara syariah, sedangkan yang lainnya, jilbab dan kerudung lebih dimaknai sebagai jilbab yang non-syariah. Penulis tidak mendikotomikan terminologi tersebut dan lebih memaknai jilbab secara terbuka ketimbang memperdebatkan sebuah terminology.

ii The Meaning of Hijab: Voices of Muslim Women in Egypt and Yemen. Journal of International Womens Studies volume 16. Bridgewater State University.

iii Risnayanti dan Cangara, 2011. Jurnal Komunikasi KAREBA Vol.1 No.2 April-Juni 2012.

iv Dalam kamus KBBI, tidak ditemukan kata Hijabers. Ejaan yang disempurnakahan adalah Hijab, yang berarti dinding yang membatasi sesuatu dengan yang lain, dinding yang membatasi hati manusia dengan Allah SWT. Hijab dalam prakteknya sebagai kebiasaan masyarakat elit Bizantium (Turki), Yunani, dan Kekaisaran Persia (Iran). Lebih jelas lihat http://www.oxfordislamicstudies.com/article/opr/t125/e839.

${ }^{v}$ Budiastuti, 2012. Jilbab dalam Perspektif Sosiologi, Studi Pemaknaan Jilbab di Lingkungan Fakultas Hukum UMJ.

${ }^{v i}$ Faeghe Shirazi, How the hijab has grown in a fashion industry. https://theconversation.com/how-the-hijabhas-grown-into-a-fashion-industry-74740 (diakses 2017)

vii ibid

viii Dalam pegumpulan data, penulis hanya menggunakan responden yang jumlahnya kecil karena alasan keterbatasan waktu dan biaya namun saya anggap bisa merepresentasikan fenomena yang ada dalam penggunaan jilbab di kalangan muslimah di Universitas Muhammadiyah Kendari.

${ }^{\mathrm{ix}}$ Konsepsi Berger ini melihat bahwa masyarakat terjadi karakterisasi seperti ini dimana individu mengesternalisasi keberadaannya dalam dunia social kemudian menginternalisasinya kedalam kenyataan obyektif yang tentu larut dan berpartisipasi dalam dialektika tersebut. (baca Peter L. Berger \& Thomas Luckmann. Tafsir Sosial atas Kenyataan. 1990. LP3ES. Jakarta (terjemahan).

${ }^{\times}$Di Google, ada 1.120 .000 .000 hasil pencarian terkait dengan Rina Nose melepas hijab. Banyak yang mendukung tapi tidak sedikit yang menghujat atas keputusannya melepas hijab.

${ }^{x i}$ Ritzer \& Goodman, 2008. Teori Sosiologi Modern Edisi ke-6. Kencana Pranada Media Group. Jakarta.

xii Chris Barker, 2009. Cultural Studies, Teori dan Praktik. Kreasi Wacana

xiii Jean Baudrillard. Masyarakat Konsumsi. Kreasi Wacana. Yogyakarta

${ }^{x i v}$ Elis Z. Anis. 2013. Islam Ala Iklan Komodifikasi Identitas Keislaman Dalam Iklan di Televisi Indonesia. Artikel bisa diunduh di:

http://download.portalgaruda.org/article.php?article=360819\&val=7520\&title=Islam\%20Ala\%20lklan\%20\%20 Komodifikasi\%20ldentitas\%20Keislaman\%20dalam\%20Iklan\%20Di\%20Televisi\%20Indonesia

${ }^{x v}$ ibid

xvi Chris Barker, 2009. Cultural Studies, Teori dan Praktik. Kreasi Wacana
} 